\title{
The contribution of tropical cyclones to the atmospheric branch of Middle America's hydrological cycle using observed and reanalysis tracks
}

\author{
Armenia Franco-Díaz ${ }^{1}\left[\right.$ ] Nicholas P. Klingaman ${ }^{2} \cdot$ Pier Luigi Vidale $^{2} \cdot$ Liang Guo $^{2} \cdot$ Marie-Estelle Demory $^{3}$
}

Received: 18 January 2019 / Accepted: 31 July 2019 / Published online: 9 August 2019

(c) The Author(s) 2019

\begin{abstract}
Middle America is affected by tropical cyclones (TCs) from the Eastern Pacific and the North Atlantic Oceans. We characterize the regional climatology (1998-2016) of the TC contributions to the atmospheric branch of the hydrological cycle, from May to December. TC contributions to rainfall are quantified using Tropical Rainfall Measuring Mission (TRMM) Multi-satellite Precipitation Analysis (TMPA) product 3B42 and TC tracks derived from three sources: the International Best Track Archive for Climate Stewardship (IBTrACS), and an objective feature tracking method applied to the Japanese 55-year and ERA-Interim reanalyses. From July to October, TCs contribute 10-30\% of rainfall over the west and east coast of Mexico and central Mexico, with the largest monthly contribution during September over the Baja California Peninsula (up to $90 \%$ ). TCs are associated with 40-60\% of daily extreme rainfall (above the 95th percentile) over the coasts of Mexico. IBTrACS and reanalyses agree on TC contributions over the Atlantic Ocean but disagree over the Eastern Pacific Ocean and continent; differences over the continent are mainly attributed to discrepancies in TC tracks in proximity to the coast and TC lifetime. Reanalysis estimates of TC moisture transports show that TCs are an important moisture source for the regional water budget. TC vertically integrated moisture flux (VIMF) convergence can turn regions of weak VIMF divergence by the mean circulation into regions of weak VIMF convergence. We discuss deficiencies in the observed and reanalysis TC tracks, which limit our ability to quantify robustly the contribution of TCs to the regional hydrological cycle.
\end{abstract}

Keywords Tropical cyclones $\cdot$ Middle America $\cdot$ Rainfall $\cdot$ Moisture transport

\section{Introduction}

Middle America, a continental region that includes Mexico and Central America, is influenced by various precipitating weather systems that drive the regional hydrology. During the warm season, this region is subject to landfalling tropical cyclones (TCs), which include tropical depressions, tropical storms and hurricanes from the Eastern Pacific and the

Armenia Franco-Díaz

a.francodiaz@pgr.reading.ac.uk

1 Department of Meteorology, University of Reading, P. O. Box 243, Reading RG6 6BB, UK

2 National Centre for Atmospheric Science, Department of Meteorology, University of Reading, Reading, UK

3 Department of Environmental Systems Science, Institute for Atmospheric and Climate Science, ETH Zürich, Zurich, Switzerland
North Atlantic basins. During September 2013, TCs Ingrid and Manuel simultaneously made landfall in the western coast of Mexico and eastern Mexico, respectively, bringing very heavy rains to a large portion of Mexico and causing deadly mudslides and flash flooding (LeComte 2014). During summer, other weather systems also contribute to rainfall, including isolated thunderstorms, synoptic and mesoscale convective systems associated with the activity of easterly waves (EWs) (Serra et al. 2016; Vigaud and Robertson 2017). Tropical EWs are synoptic-scale precursors of TCs in both the Northeast Pacific and North Atlantic (Belanger et al. 2016). Eastern Pacific and North Atlantic vertical wind shear and sea surface temperatures (SSTs) favour cyclogenesis during boreal summer and early autumn (Molinari et al. 2000).

The influence of TCs on the hydrological cycle has been examined by many studies (e.g. Larson et al. 2005; Jiang and Zipser 2010; Prat and Nelson 2013a, b, 2016; Guo et al. 2017; Xu et al. 2017). Prat and Nelson (2013b) found that 
$8-12 \%$ of rainfall are attributable to TCs in the Southeastern United States (US) for inland areas located between 150 and $300 \mathrm{~km}$ from the coast and $15-20 \%$ along the coast. TCs account for $50-70 \%$ of daily accumulations above $100 \mathrm{~mm} \mathrm{day}^{-1}\left(\sim 4 \mathrm{in} \mathrm{day}^{-1}\right)$ along the U.S. Atlantic coast from Florida to New England (Prat and Nelson 2016). Over the coastal region of Eastern Asia, TCs contribute 10-30\% of the monthly total rainfall, and around $50 \%$ of the occurrence of extreme daily rainfall [above the 95th percentile] (Guo et al. 2017). TCs contribute approximately $10 \%$ of the total moisture transport to the East Asia coast (Guo et al. 2017), and $14 \%$ to the North American coast (Xu et al. 2017). Positive global trends in TC-associated rainfall are expected (Kossin 2018). Only a few studies have evaluated the contribution of TCs to the atmospheric branch of Middle America's hydrological cycle: Larson et al. (2005) found summer TC-related rainfall contributions exceeding $20 \%$ along the southwest coast of Mexico, using rain gauge observations. Jiang and Zipser (2010) found that TCs contribute about $55 \%$ of yearly rainfall over Baja California, Mexico. Prat and Nelson (2013a) found that near 15\% of yearly rainfall over Mexico's Pacific Coast is related to TCs; later, Prat and Nelson (2016) quantified that up to $32 \%$ of the precipitation is associated with TCs along the Gulf of Mexico and 50\% in southern Baja California; TCs accounted for almost all daily accumulations above $100 \mathrm{~mm}_{\text {day }}{ }^{-1}$ over Baja California. Over semiarid regions of Mexico TCs may contribute up to $50 \%$ of the seasonal rainfall (Domínguez and Magaña 2018). To complement these previous studies, we analyse the monthly climatology of the contribution of TCs over Middle America, including the effect of TCs on extreme rainfall.

TC contributions to the atmospheric moisture transport and their role in the Middle America's moisture budget have received little attention. In view of such a gap, we develop a climatology of the monthly contribution of TCs to the atmospheric moisture transport over Middle America. Several methodologies for quantifying the contribution of TCs to rainfall (Prat and Nelson 2016; Guo et al. 2017) and moisture transport (Prat and Nelson 2013b, 2016; Guo et al. 2017; Xu et al. 2017) employing an Eulerian framework have been developed, which require a set of TC tracks. A variety of TC track datasets are available, including those based on observations, as well as those obtained from objective feature tracking methods applied to reanalysis data.

All sources of TC track data involve uncertainties. For observed tracks, there are uncertainties related to location and intensity, superimposed on operational differences between agencies in TC identification. These uncertainties are greatest for the weakest storms, as well as during the preTC and post-TC stages for all storms (Hodges and Emerton 2015). To fill this gap, TC tracks from reanalyses can complement the observations, providing added value information on earlier and later stages of the TCs life cycle (Hodges et al. 2017). Hodges et al. (2017) applied their objective tracking method to reanalysis and found that the largest uncertainties in TC identification come from the representation of TC intensities and structure. Differences between reanalyses are expected due to variations in dynamical core and physical parameterizations, the data assimilation methods, as well as their model grid resolution (Hodges et al. 2017). Previous studies typically have quantified the TC contribution to the hydrological cycle using either observed or reanalysis tracks. To investigate the uncertainty due to the source of TC track data, we quantify TC contributions to precipitation using observed tracks and tracks from two state-of-the-art reanalyses.

In this paper, we characterize the regional climatology of the TCs contribution to the atmospheric branch of the hydrological cycle over Middle America, from May to December, also exploiting the advantages and considering the uncertainties associated with the representation of TCs identified in observations and reanalyses. To achieve this purpose, we quantify the mean monthly rainfall (Sect. 3.1) and extreme daily rainfall associated with TCs (Sect. 3.2), employing and comparing trajectories identified from observations and two reanalyses. We also quantify monthly moisture flux and moisture divergence associated with TCs for these two reanalyses (Sect. 3.3).

\section{Data and methods}

\subsection{Observations}

Monthly contributions of TCs at regional scale are computed using satellite rainfall estimates from the Tropical Rainfall Measuring Mission (TRMM) Multi-satellite Precipitation Analysis (TMPA 3B42) for 1998-2016. Version 7 TMPA $3 \mathrm{~B} 42$ provides estimates of rainfall for $50^{\circ} \mathrm{S}-50^{\circ} \mathrm{N}$, at $0.25^{\circ} \times 0.25^{\circ}$ spatial resolution and 3-h temporal resolution (Huffman and Bolvin 2015). Historical records of TCs from various official meteorological agencies worldwide, obtained from the International Best Track Archive for Climate Stewardship (IBTrACS) dataset (Knapp et al. 2010), are used to identify observed TCs. The IBTrACS dataset is a global repository of TC best-track data from Regional Specialized Meteorological Centers (RSMCs) and other agencies around the world, which provides 6-h information for each tropical storm such as its location, intensity, central pressure, among others. The primary data source in the North Atlantic and the East Pacific basins is the Atlantic Hurricane Database (HURDAT; Landsea and Franklin 2013) from RSMC Miami. The HURDAT dataset is already a best-track dataset for the Atlantic basin. TC-related rainfall quantified by using IBTrACS are compared to that quantified by using TC tracks 
from an objective tracking method (described in Sect. 2.3) applied to two recent global atmospheric reanalysis datasets, (a) the European Centre for Medium-Range Weather Forecasts (ECMWF) interim reanalysis (ERA-Interim; Dee et al. 2011) and (b) the Japanese 55-year reanalysis (JRA-55; Kobayashi et al. 2015), described below.

\subsection{Reanalysis datasets}

ERA-Interim and JRA-55 reanalyses datasets are used for TC trajectory identification and moisture transport calculations. Six-hourly $(0000,0600,1200$, and 1800 UTC) ERAInterim variables used in this study include temperature, winds, vorticity (native resolution of T255, $60 \mathrm{~km}$ ), specific humidity on pressure levels, and vertically integrated moisture fluxes and their divergence (regular grid with a resolution of $\left.0.78^{\circ} \times 0.78^{\circ}\right)$. Six-hourly JRA-55 reanalysis variables of vorticity and temperature, winds on pressure levels, and vertically integrated moisture fluxes (all at the original resolution of TL319, $55 \mathrm{~km}$ ) are used in this study; the divergence of JRA-55 vertically integrated moisture fluxes fields are computed using spherical harmonics with truncation T64, employing the windspharm Python package (Dawson 2016). An important feature of the JRA-55 is the assimilation of tropical wind retrievals to improve the representation of TC intensity. The wind profile surrounding and over each observed TC centre is retrieved from historical data during the processing and assimilation, in a way that observations are used to simulate data from a dropsonde (Hatsushika et al. 2006; Hodges et al. 2017).

\subsection{TC feature tracking methodology}

The objective TC tracking method based on Hodges (1994, $1995,1999)$ is applied separately to each reanalysis dataset. The method [fully described in Hodges et al. (2017)] consists on firstly identifying the tropical disturbances using relative vorticiy fields, vertically averaged from 850 to $600 \mathrm{hPa}$; through the use of a spectral filter (Sardeshmukh and Hoskins 1984), tropical systems with wavenumbers between 6 and 63 are retained. A second step consists of applying a direct spaceand time- matching criterion between the identified tropical systems tracks from the reanalysis and the observed IBTrACS tracks. This criterion allows matching both tracks when the distance between them is no more than 4 geodesic degrees, at the same time that they overlap in time. Hodges et al. (2017) found that, under this criterion, the probabilities of detection for the Northern Hemisphere for TCs obtained from JRA-55 and ERA-Interim reanalyses that match with IBTrACS and/ or hurricanes category $1-5$, are 0.95 and 0.81 , respectively. Afterwards, for the detection of a TC, a threshold criterion of vertically decreasing vorticity is applied to the filtered vorticity fields (across $850-250 \mathrm{hPa}$ ) to detect the typical warm core vertical structure of a TC. With this objective TC tracking method it is possible to detect the precursor and postextratropical transition stages of the $\mathrm{TC}$, which results in an extended description of the life cycle of the TC compared to observed tracks from IBTrACS (Hodges et al. 2017).

\subsection{Quantifying the contribution of TCs to rainfall and moisture fluxes}

A total of 19 TC seasons (from 1998 to 2016) of the Pacific and the Atlantic oceans have been analysed to quantify the contribution of TCs to rainfall. To study the spatial distribution of the rainfall attributed to TCs, the TC season is subdivided into 8 months, from May to December. To investigate the contribution of TCs to rainfall over Middle America, 3-h TMPA 3B42 rainfall within 5 geodesic degrees radius centred over the TC location is identified as TC associated rainfall (e.g. Larson et al. 2005; Jiang and Zipser 2010; Guo et al. 2017); the rest of the rainfall is masked as non-TCrelated rainfall. The 5 geodesic degrees radius criterion captures the primary wind circulation domain of the TC, commonly located between 80 and $400 \mathrm{~km}$ from the TC centre, as well as part of the TC cloud shield, commonly found at 550-600 km (Prat and Nelson 2013b). Although the aforementioned TC fixed radius is commonly chosen in TC-related rainfall and moisture transport studies, in some cases this assumption does not capture the full extent of the TC (e.g. Xu et al. 2017). Since the temporal interval of the TC position for all the track datasets is $6 \mathrm{~h}$, two consecutive $3 \mathrm{~h}$ steps of TMPA 3B42 rainfall are applied to the same TCassociated mask. To investigate the contribution of TCs to extreme rainfall, we first compute the extreme daily rainfall, defined as the frequency of daily events that exceed the 95th percentile of the TMPA 3B42 daily accumulated rainfall for each month and grid point during 1998-2016. A 5 geodesic degrees radius mask centred over the TC location is then applied to the daily rainfall to further obtain the fraction amount (intensity) and fraction count (frequency) of daily extreme events related to TCs.

Following the methodology of Guo et al. (2017), we analyse the contribution of TCs to the regional monthly moisture transport over Middle America for a total of 38 TC seasons (from 1979 to 2016), employing the horizontal wind $(v)$ and the specific humidity $(q)$ fields of the 6-h ERAInterim and JRA-55 reanalyses. Time means of $v$ and $q$ refer to monthly climatologies of horizontal wind $(\bar{v})$ and specific humidity $(\bar{q})$, respectively, over 1979-2016. Moisture flux fields (derived from $v$ and $q$ ) are decomposed into time-mean and eddy (deviation from the time-mean) terms, following the equation:

$$
\begin{aligned}
& v q=\left(\bar{v}+v^{\prime}\right)\left(\bar{q}+q^{\prime}\right) \\
& v q=\left(\bar{v}+v_{T C}^{\prime}+v_{n o n-T C}^{\prime}\right)\left(\bar{q}+q_{T C}^{\prime}+q_{n o n-T C}^{\prime}\right)
\end{aligned}
$$


where $v q$ represents the total moisture flux field. The deviations from the time-mean values (eddies) of the wind field and the specific humidity are represented by the terms $v^{\prime}=v-\bar{v}$ and $q^{\prime}=q-\bar{q}$, respectively. The eddy component terms related to TCs of Eq. $1, v_{T C}^{\prime}$ and $q_{T C}^{\prime}$, are obtained using the criterion of 5 geodesic degrees radius mask centred over the TC location, applied to the 6-h eddy wind field $\left(v^{\prime}\right)$ and to the eddy specific humidity field $\left(q^{\prime}\right)$, respectively. The total moisture flux $(v q)$ at each pressure level is subdivided into the transport of mean moisture by the mean horizontal wind $(\bar{v} \bar{q})$, the moisture transport by non-TC eddies $\left((v q)_{n o n-T C}^{\prime}\right)$, and the moisture transport by TC eddies $\left((v q)_{T C}^{\prime}\right)$, the latter represented by the equation:

$(v q)_{T C}^{\prime}=\bar{v} q_{T C}^{\prime}+v_{T C}^{\prime} \bar{q}+v_{T C}^{\prime} q_{T C}^{\prime}$

where the first term of the right-hand side of Eq. 2 represents the transport of TC eddy moisture by the mean horizontal wind $\left(\bar{v} q_{T C}^{\prime}\right)$, the second term represents the transport of mean moisture by the TC eddy horizontal wind $\left(v_{T C}^{\prime} \bar{q}\right)$, and the third term represents the transport of TC eddy moisture by the TC eddy horizontal wind $\left(v_{T C}^{\prime} q_{T C}^{\prime}\right)$. A subsequent analysis of the contribution of TC on the water balance for the region uses vertically integrated moisture flux (hereafter VIMF) divergence fields from ERA-Interim and JRA-55 reanalyses, integrated throughout the atmospheric column. The VIMF divergence field relates the mean balance of evaporation $(\bar{E})$ and precipitation $(\bar{P})$ : divergence means that, in the long term, evaporation exceeds precipitation $(\bar{E}-\bar{P}>0)$, indicating a source of water vapour to the atmosphere from the region. The sinks of atmospheric water vapour are identified as regions of VIMF convergence where precipitation exceeds evaporation $(\bar{E}-\bar{P}<0)$.

\section{Results}

\subsection{Contribution of tropical cyclones to the mean accumulated rainfall over Middle America}

From the observed tracks (IBTrACS), the contribution of the TCs to the monthly mean rainfall over the continent is more noticeable during June, and August to October (Fig. 1), being larger over the southeast coast of the US, and the Mexican west and east coasts during September, followed by the central/southern Mexico and Central America during October. From mid-August to late October, the Eastern Pacific Ocean and the North Atlantic (Gulf of Mexico and the Caribbean) show a peak in TC activity (Gilford et al. 2017; NHC 2018) and with more frequent landfalls than in other stages of the hurricane season (e.g. Prat and Nelson 2013b). The simultaneous increase in TC activity in both basins affects a wide portion of the south and centre of Mexico, mainly during October, when North Atlantic and
Eastern Pacific TCs together contribute about $10-20 \%$ of the monthly-accumulated rainfall (Fig. 2).

The largest climatological contributions of TCs to the accumulated rainfall over the Gulf of Mexico, the east coast of Mexico, and the US southeast coast are found during September, with about $10-20 \%$ of the monthly rainfall (Fig. 2). The effect of TCs on the regional rainfall extends along the Gulf Coastal Plain, which reaches from eastern to northeastern Mexico through the Yucatan Peninsula, continues along Tabasco and Veracruz to Tamaulipas, and extends around the Gulf of Mexico in the Southern US. Our results suggest that the effect of the Atlantic TCs on precipitation is in part constrained by the orographic features of the region, with the largest contribution over the Gulf Coastal Plain. During the majority of the months analysed, the contributions of TCs to the rainfall over the southern portion of Mexico's coastline are between 10 and $20 \%$ of the total precipitation, covering almost the entire Yucatan Peninsula. Throughout July, August and September, rainfall associated with the Atlantic TCs extends further north within the domain of Middle America, having a noticeable effect inland, contributing $10 \%$ of rainfall over the northeast of Mexico in the states of Tamaulipas and Nuevo Leon (beyond $200 \mathrm{~km}$ inland), especially over portions of land below $1500 \mathrm{~m}$ altitude.

In climatological terms, the eastern North Pacific is the most active ocean basin for the genesis of TCs, per unit area and time (Molinari et al. 2000). East Pacific TCs have an important effect on the summer rainfall of continental Middle America. The TC-related rainfall over the west coast of Mexico is strongly influenced by the presence of the Sierra Madre Occidental, Mexico's longest mountain range, which stretches $1100 \mathrm{~km}$ through North-western and Western Mexico. The results show a pattern of TC-related rainfall that extends along the coast next to the Gulf of California and the Gulf of Tehuantepec. Over this large continental area, the largest contribution of TCs to climatological rainfall occurs during the last three months of the TC season. TCs account for between 10 and $50 \%$ of the rainfall along the Northwest coast of Mexico, and can contribute as much as $10 \%$ to the seasonal rainfall in the western interior locations in the states of Sonora, Chihuahua, Durango and Sinaloa, particularly during September and October, coincident with the end retreat of the North American Monsoon. TC contributions to the monthly rainfall maximise during September, over the west coast of Mexico, the centre of Mexico and the Baja California Peninsula, contributing to the latter to more than $60 \%$ of the total monthly rainfall, the largest fractional contribution of TCs over the entire domain. The high percentage contribution over Baja California is exaggerated by the low mean rainfall in the region, which is generally less during boreal summer than winter, and very low compared with other continental areas of the domain of study. In cases like Hurricane Jimena in 2009, the contribution can be more 
Fig. 1 Contribution of TCs to the mean monthly-accumulated rainfall $(\mathrm{mm})$ from May to December, quantified with observed TCs trajectories from IBTrACS and TMPA 3B42 estimates of rainfall. Climatology for 1998-2016
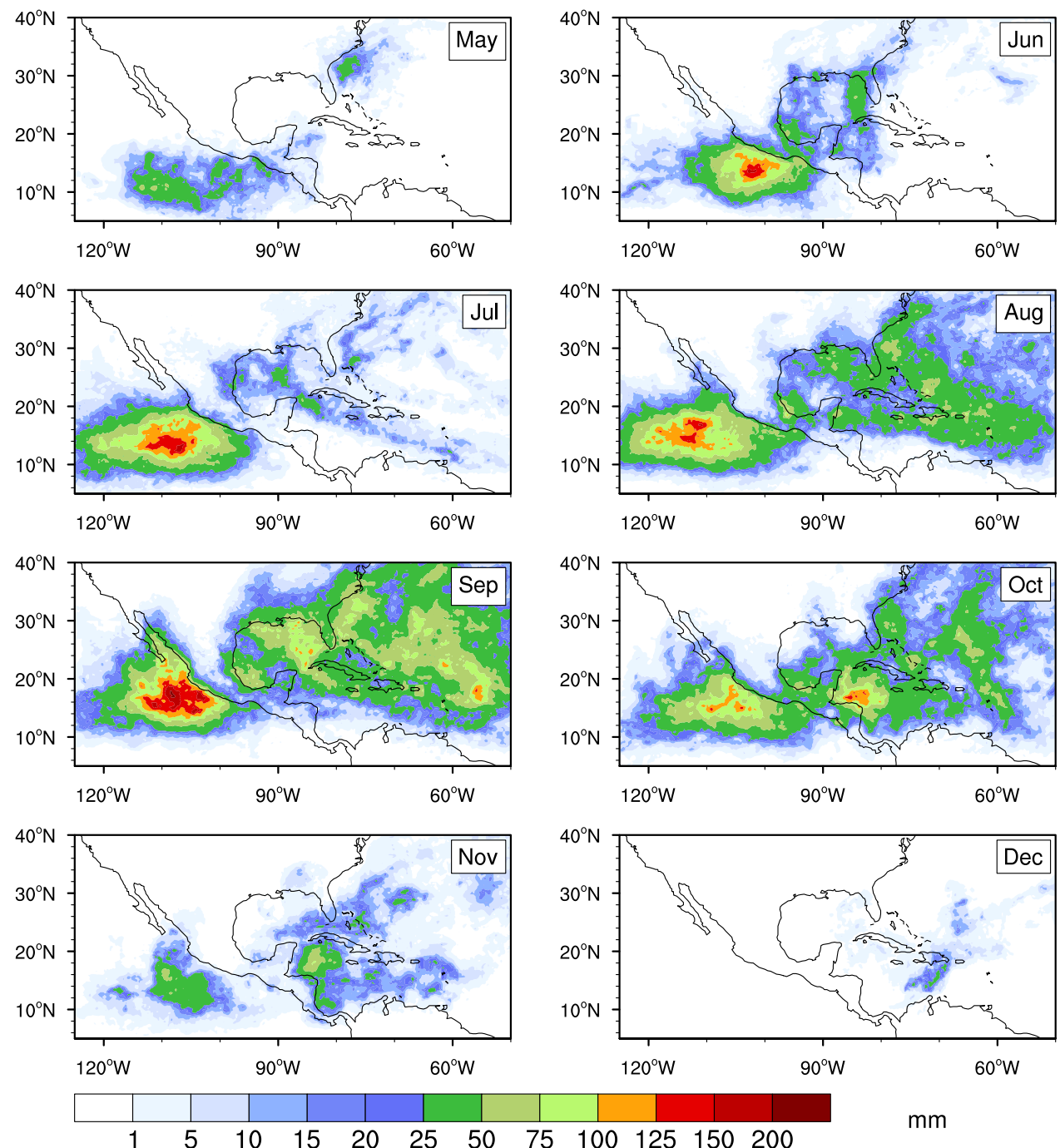

than $90 \%$ of the monthly rainfall over a large portion of the peninsula. The large-scale flow pattern necessary to turn the storms northward toward Northwest Mexico is much more likely at the end of the TC season in boreal autumn (Corbosiero et al. 2009). Another factor that favours development of TCs is the increase of the monthly mean SST to above $27{ }^{\circ} \mathrm{C}$ over the Gulf of California from July to October (e.g. Hall and Tippett 2017).

Differences between TC associated monthly rainfall calculated with IBTrACS and ERA-Interm/JRA-55 reanalyses. After estimating the contribution of TCs to precipitation using IBTrACS tracks, we now consider the same quantity by using TC tracks from the objective TC tracking method applied to ERA-Interim and JRA-55 data (described in Sect. 2.3). Figure 3 shows the differences between the monthly climatology for 1998-2016 of TC-accumulated rainfall (mm) calculated from TMPA 3B42 data, using (a)
ERA-Interim and IBTrACS tracks, and (b) JRA-55 and IBTrACS tracks.

Some agreement between the TC-associated rainfall calculated with ERA-Interim and IBTrACS tracks is found over the North Atlantic at the beginning of the TC season. The differences get larger as the season progresses, reaching monthly differences $( \pm 50 \mathrm{~mm})$ over the Caribbean Sea and the Gulf of Mexico. Throughout the season, a dipole of differences develops over the Eastern Pacific basin and Central America, with larger values in ERA-Interim in the south of the domain (with up to $100 \mathrm{~mm}$ per month), and larger values in IBTrACS further north in the basin (mainly up to 50 $\mathrm{mm}$ month $^{-1}$, located northwards $10^{\circ} \mathrm{N}$ ). Most of the negative differences are found over land, varying in location and rate each month, being larger over the west and east Mexican coasts by September. Slight reductions of TC-related rainfall (about $15 \mathrm{~mm} \mathrm{month}^{-1}$ ) using JRA-55 tracks relative to IBTrACS are found over the Caribbean Sea throughout the TC season. The largest positive differences $(25-150 \mathrm{~mm})$ are 
Fig. 2 Contribution of TCs to the mean monthly-accumulated rainfall (\%) from May to

December, quantified with observed TCs trajectories from IBTrACS and TMPA 3B42 estimates of rainfall. Climatology for 1998-2016
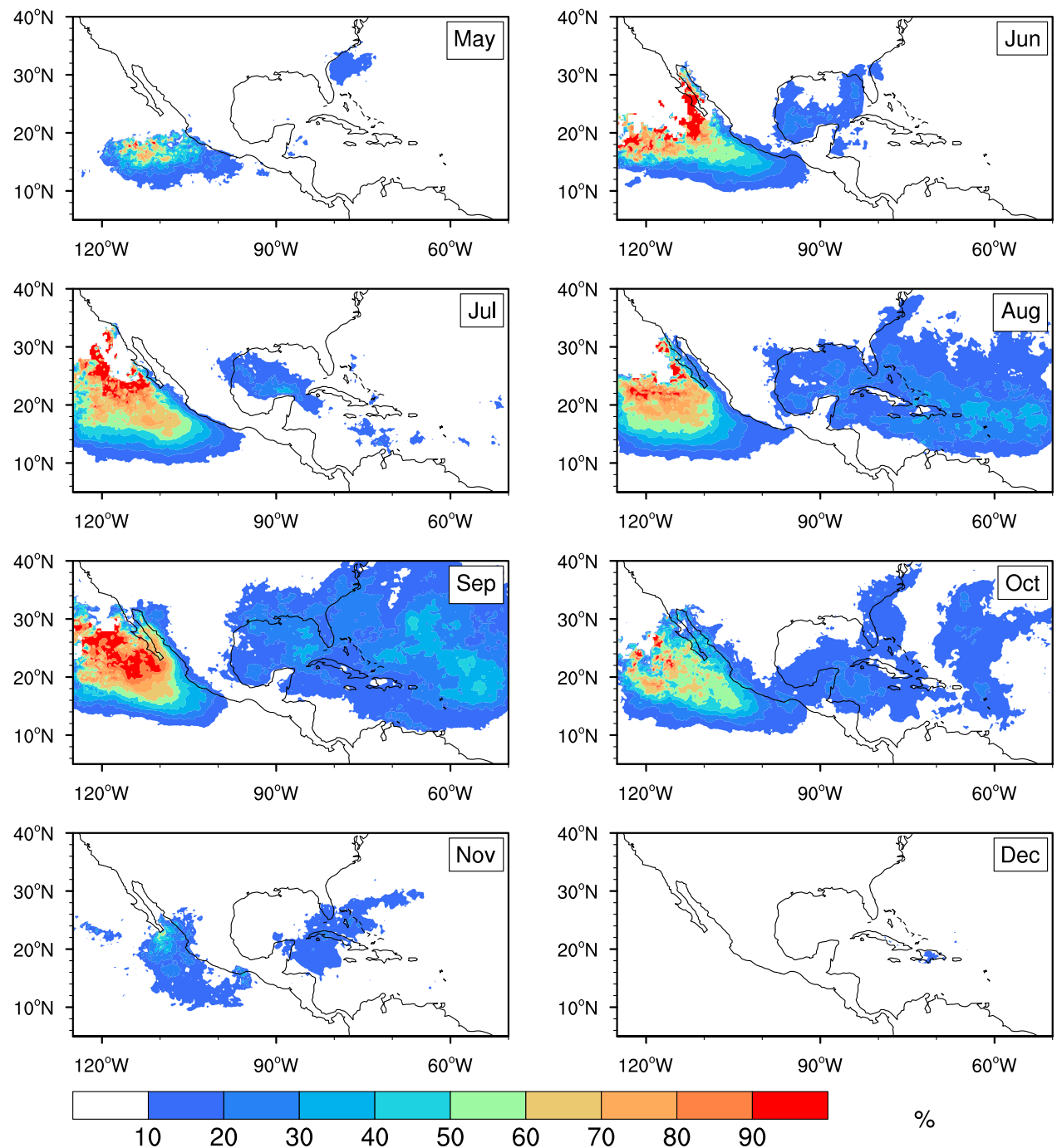

$\%$ found over Central America and the Eastern Pacific next to the southwest Mexican coast, collocated with the Eastern Pacific warm pool. Important reductions in JRA-55 relative to IBTrACS are found each month throughout the TC season over Middle America and the Southeast of the US., being more noticeable during September in the west and east coast of Mexico. The reductions are up to $50 \mathrm{~mm}$ and are widespread from the coast to inland, especially in Central Mexico, along the Gulf of Tehuantepec and the Gulf of Mexico. However, the two estimates largely agree over the North Atlantic Ocean basin, where the differences during May and August are within $\pm 15 \mathrm{~mm}$, with a minimum along the US southeast and the western Mexico coasts during June and September, respectively, and a maximum during October over the Gulf of Mexico and Central America. In general, the TC-associated rainfall calculated with JRA-55 tracks agrees more closely with IBTrACS than that calculated with ERA-Interim tracks; in both cases, the climatology obtained with the reanalyses tracks show lower TC contributions to rainfall over the continent, especially over the coasts and Central Mexico. These differences are discussed in Sect. 4.

\subsection{Contribution of tropical cyclones to the extreme rainfall over Middle America}

TCs are related to episodes of heavy rainfall, causing severe damages and losses. We examine the seasonal contributions of TCs to amounts and frequency of extreme rainfall (Fig. 4) over Middle America during July, August, September, and October (JASO), based on TC tracks from IBTrACS and on the 95th percentile of daily rainfall of each month during 1998-2016, calculated from TMPA 3B42 rainfall estimations. The percentage of amount of TC extreme rainfall represents the daily $\mathrm{TC}$ accumulated extreme rainfall relative to the total accumulated rainfall of all the extreme events; the percentage of frequency of TC extreme rainfall represents the events of extreme rainfall related to TCs relative to all the extreme rainfall events. 
(a)
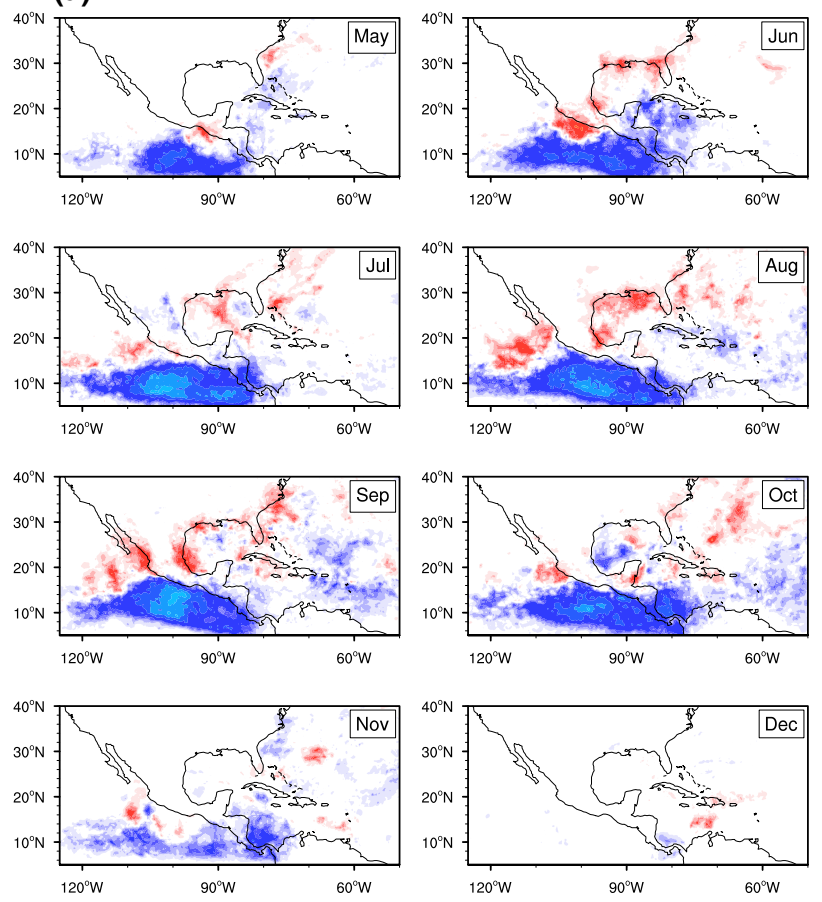

(b)
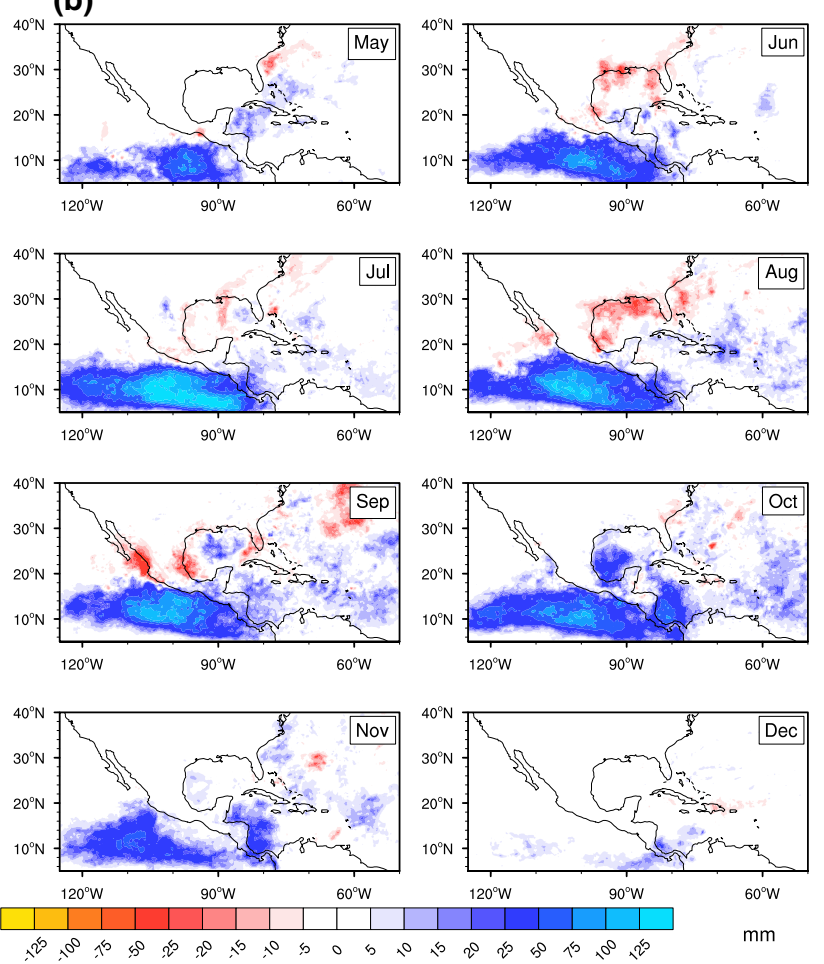

Fig. 3 Differences between the contributions of TCs to the mean monthly-accumulated rainfall $(\mathrm{mm})$ quantified with TMPA 3B42 estimates of rainfall and with TC trajectories based on a ERA-Interim reanalysis and IBTrACS, and on b JRA-55 reanalysis and IBTrACS, from May to December (1998-2016)
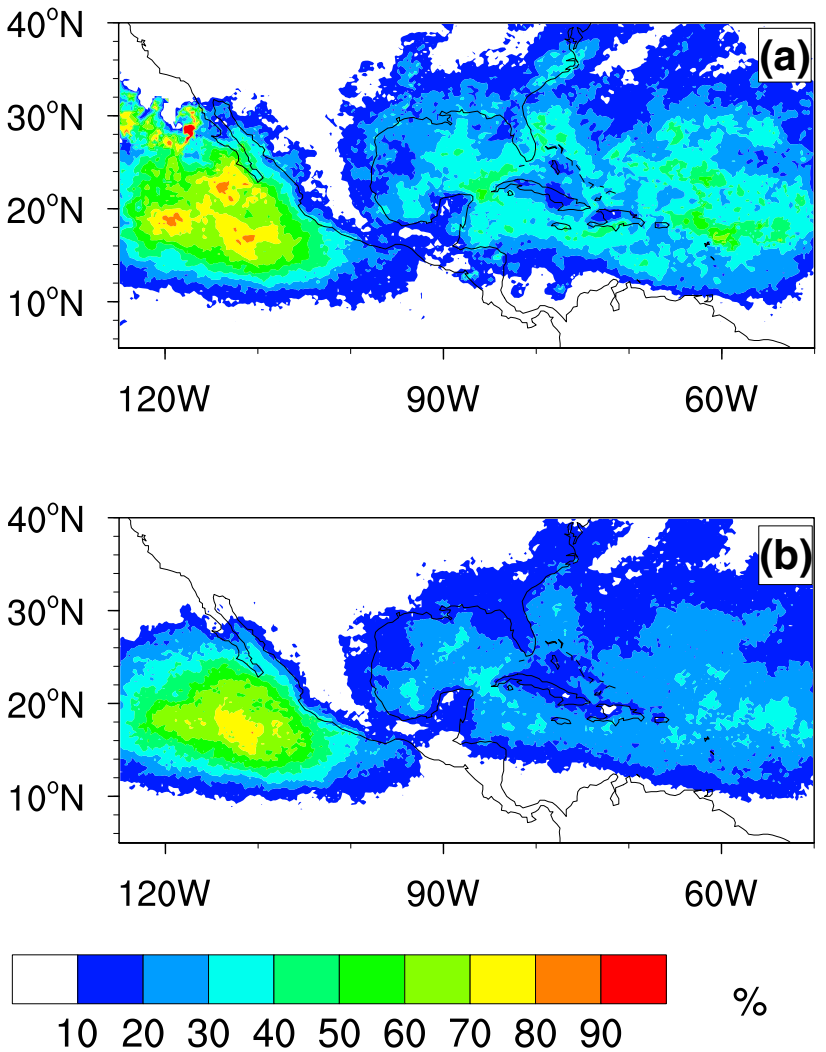

Fig. 4 Mean contribution of TCs to the extreme rainfall a amount (\%) and $\mathbf{b}$ frequency (\%) during JASO, employing TCs tracks from IBTrACS. Climatology for 1998-2016

During JASO, the highest contributions of TCs to the extreme rainfall amounts and frequencies over the continent are found over a large area of the Baja California Peninsula, followed by the west coast of Mexico, and much of the Gulf Coastal Plain. The relative values of the contributions of TCs to extreme rainfall amount and frequency define regions where the TC-related extreme rainfall is heavier than extreme rainfall from systems unrelated to TCs: larger values of amount than frequency indicate that TC-related extreme rainfall, per event, is heavier than non-TC extreme rainfall, per event. For example, this occurs over the Baja California Peninsula, part of the northwest of Mexico, and along the Gulf Coast of the United States, where the amount TCrelated extreme rainfall exceeds the frequency by more than $10 \%$.

To further examine the seasonal cycle of the TC contribution to the regional extreme rainfall, we examine the monthly contributions of TCs to extreme rainfall amounts and frequency of extreme rainfall (Figs. 5, 6, respectively) during July, August, September and October, based on the 95th percentile of daily rainfall of each month during 1998-2016, calculated from TMPA 3B42 rainfall estimations. Observations 
(a) IBTrACS
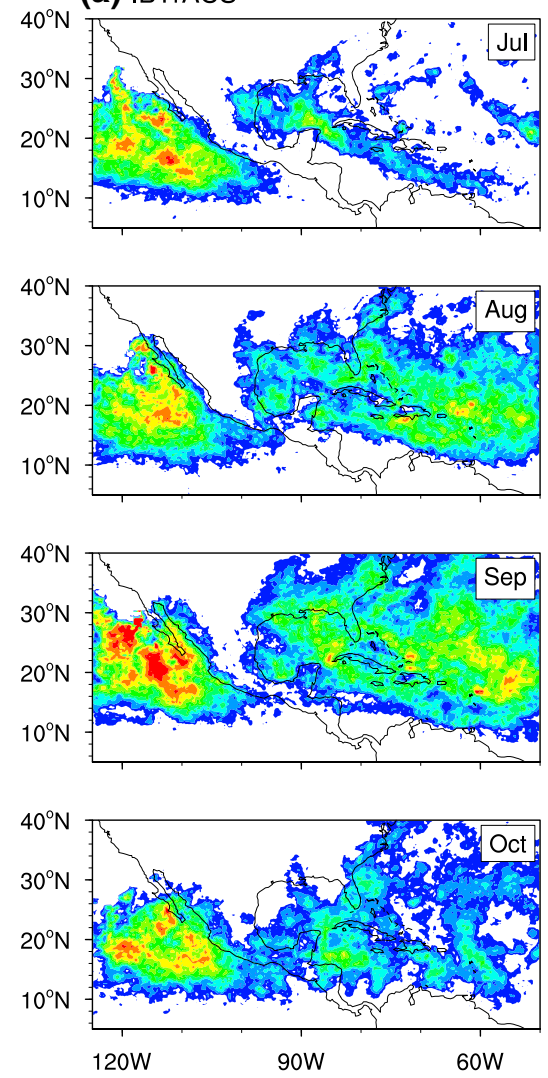

(b) ERA-Interim
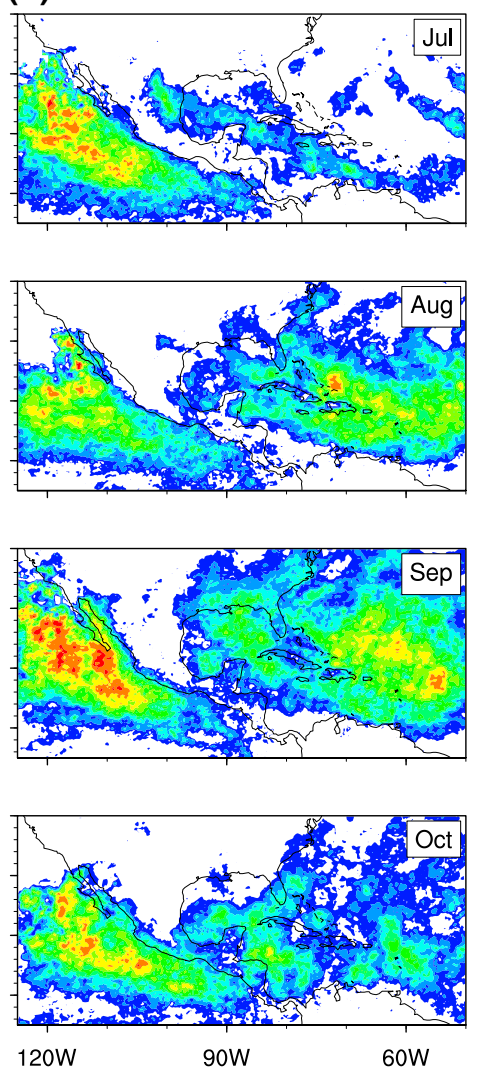

$120 \mathrm{~W}$ (c) JRA-55
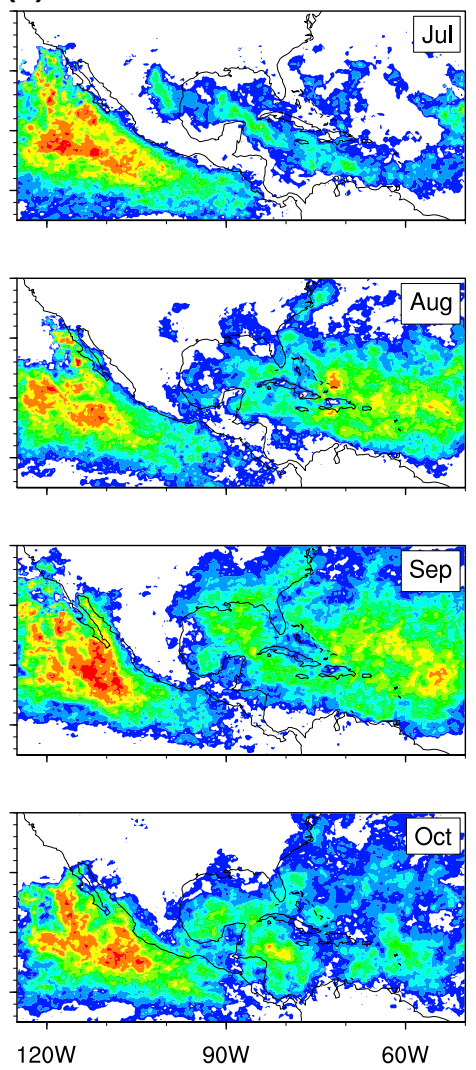

$\%$

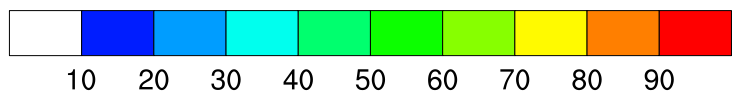

Fig. 5 Monthly contributions of TCs to the extreme rainfall amount (\%) from July to October, employing TCs tracks from a IBTrACS, b ERAInterim, and c JRA-55. Climatology for 1998-2016

and reanalyses show that the highest contribution of TCs to extreme rainfall occurs on the east coast of Mexico during September and October, with extreme rainfall amounts mainly between 20 and $50 \%$ of the total extreme rainfall amount (Fig. 5). The largest inland contribution of TCs to extreme rainfall amount occurs during September over the Baja California Peninsula and the Gulf Coast of the US, with up to $60 \%$ and $50 \%$ of the extreme rainfall amount, respectively, followed by northwestern Mexico (encompassing an area that includes the states of Tamaulipas, Nuevo Leon and Coahuila) with up to $50 \%$ during July. The amount of TC-related extreme rainfall exceeds the frequency by more than $10 \%$ over much of the northeast of Mexico during July, over the Baja California Peninsula from August to October, and throughout the season over some portions of the Gulf Coast of the US, Central and Southern Mexico, Nicaragua, Honduras, and the Caribbean.

Most of the agreement between the contribution of TCs to the monthly extreme rainfall using IBTrACS and reanalysis tracks is found over the Atlantic Ocean and over the Middle
America landmass, whereas some differences are found over the Pacific Ocean. The contribution of TCs to extreme rainfall amounts and frequency obtained from the reanalysis tracks is more than that obtained from IBTrACS over the some portions of the Eastern Pacific Ocean between $5^{\circ} \mathrm{N}-10^{\circ} \mathrm{N}$.

\subsection{Contribution of tropical cyclones to moisture transport over Middle America}

The hydrological cycle includes processes of evaporation, condensation, precipitation, and moisture advection, which represent the means whereby water is added to or removed from the atmospheric branch. The atmospheric water vapour availability and transport play an important role in determining the climate over the continents, and are strongly linked with radiative processes (e.g. Trenberth and Fasullo 2009), with convection and the generation of rainfall (Grabowski and Moncrieff 2004). Of particular interest to this study is the spatial distribution of the TC-related moisture transport and 
its contribution to the climatological moisture transport relative to the contribution from the mean circulation over Middle America. Figure 6 represents the spatial distribution of the monthly-accumulated VIMF (arrows) and VIMF divergence (shading) by the mean circulation $(\nabla \cdot(\overline{v q}))$ from (a) ERAInterim and (b) JRA-55 for 1979-2016. During the TC season, strong convergence is observed over most of the Eastern Pacific, while over the North Atlantic it is confined to a band between $5^{\circ}$ and $10^{\circ} \mathrm{N}$; in both basins the region of maximum VIMF convergence is associated with the Inter Tropical Convergence Zone (ITCZ) (Peixoto and Oort 1992) and the seasonal migration of the edges of the Hadley Cell. Divergence prevails and is less intense over the North Atlantic, especially in the north of the basin. Both reanalyses show that some portions of the Atlantic Ocean, as well as the Caribbean Sea and the Gulf of Mexico, are important moisture sources during the boreal summer. Over the Gulf of Mexico and the Caribbean, mean VIMF divergence prevails during May to August, and turns to convergence during September and October.
An analysis of the magnitude and sign of TC-related VIMF convergence shows regions where the influence of TCs becomes more relevant to the total monthly moisture transport over the domain (Fig. 7). The contribution of TCs to moisture transport, quantified with ERA-Interim and JRA55 (Fig. 8a, b, respectively), shows that monthly TC-related VIMF convergence is about an order of magnitude smaller than the VIMF divergence by the mean circulation.

In general, the TC contribution to moisture transport over the Eastern Pacific basin is larger than that over the North Atlantic basin throughout the TC season, and it has a broader spatial extent inland relative to rainfall, suggesting that TCs can affect precipitation further downstream than the 5 geodesic degree radius we specified for the quantification. Added to this, the contribution in JRA-55 is larger than in ERA-Interim possibly due to higher resolution of JRA-55 and assimilation of TC winds, sustaining stronger storms (Hodges et al. 2017). (a) IBTrACS
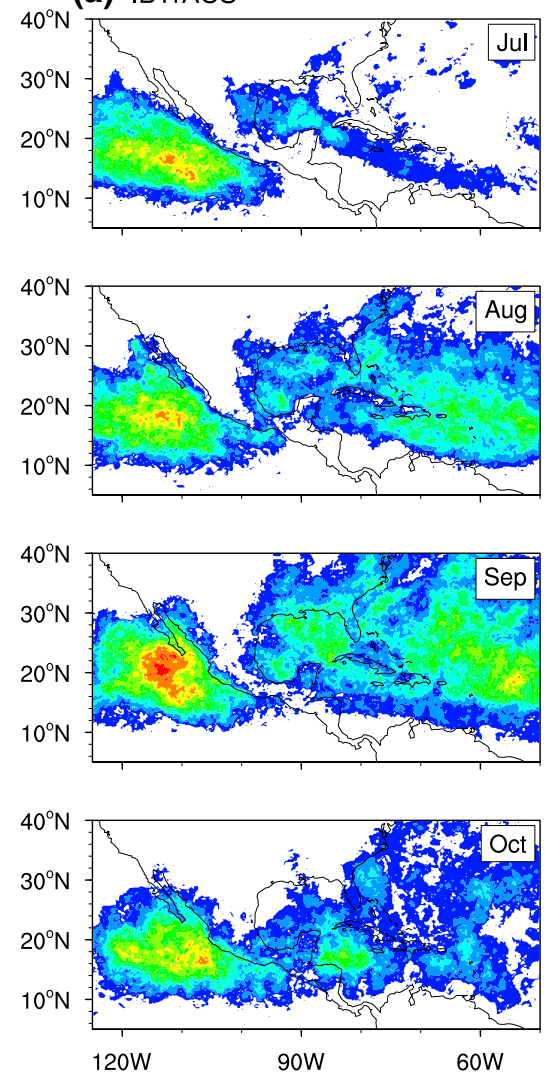

(b) ERA-Interim
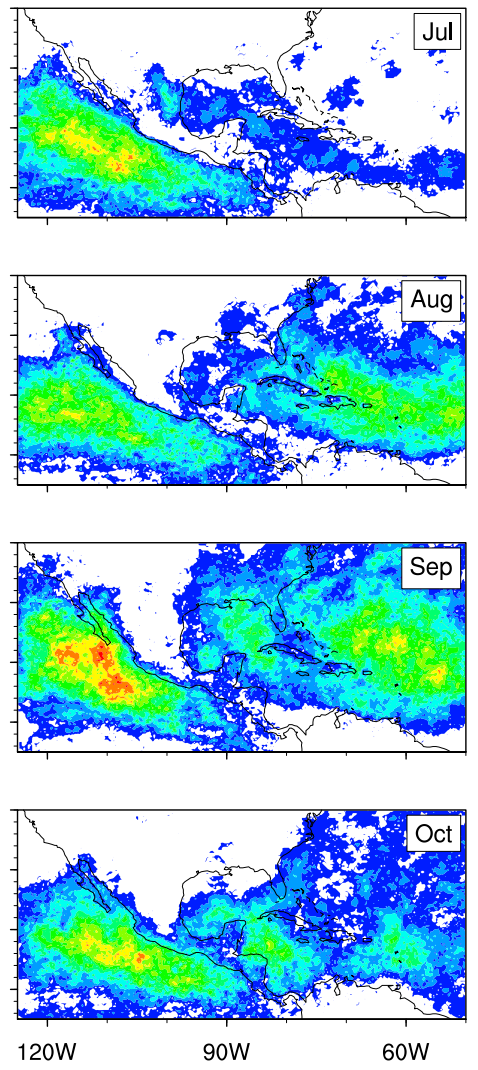

(c) JRA-55
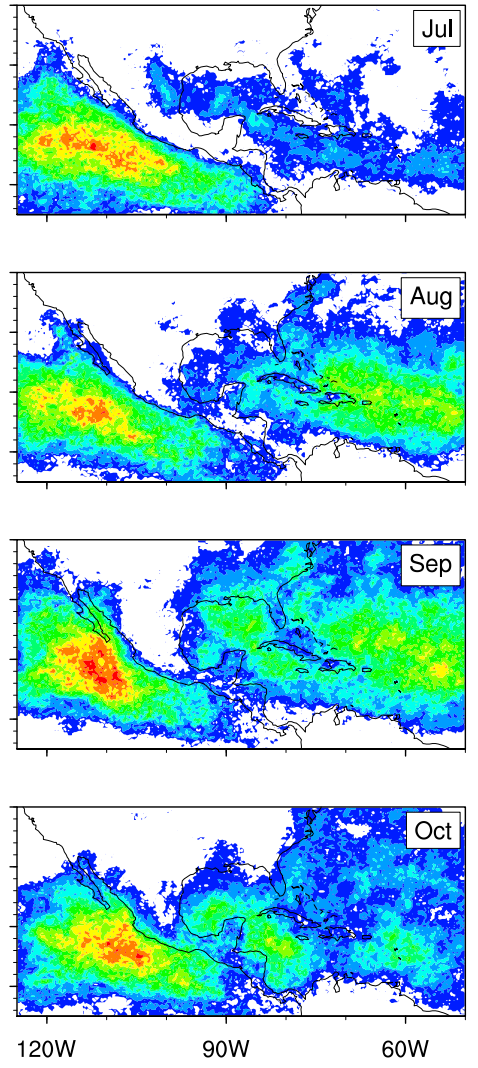

$\%$

Fig. 6 Monthly contributions of TCs to the extreme rainfall frequency (\%) from July to October, employing TCs tracks from a IBTrACS, b ERA-Interim, and c JRA-55. Climatology for 1998-2016 
(a) ERA-Interim
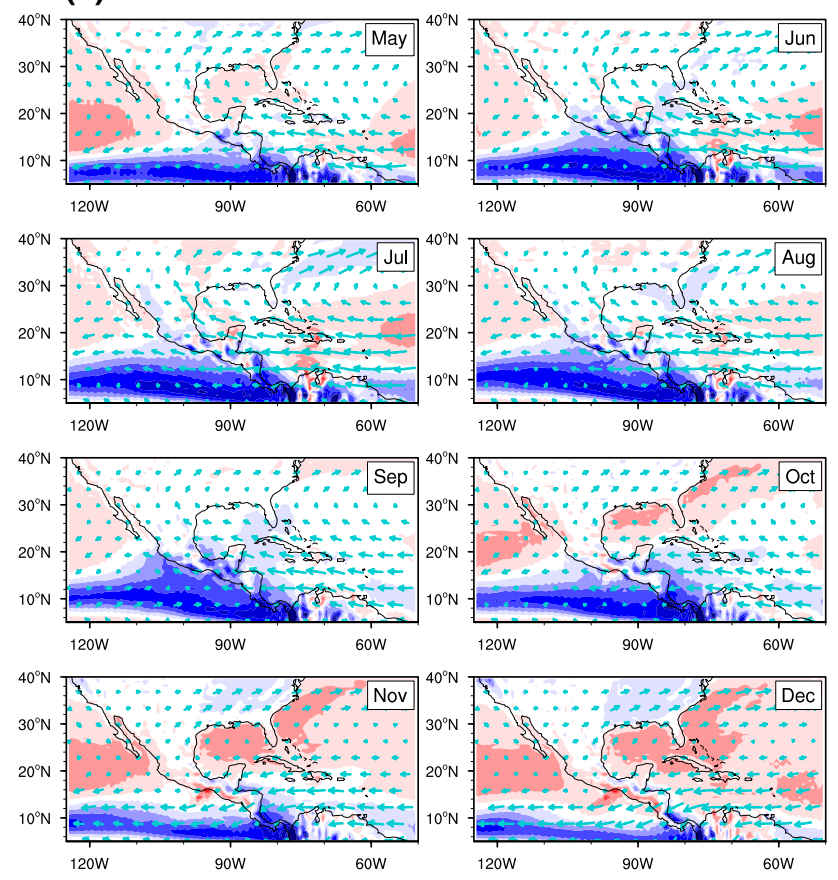

(b) ${ }_{\mathrm{JPA} .55}$
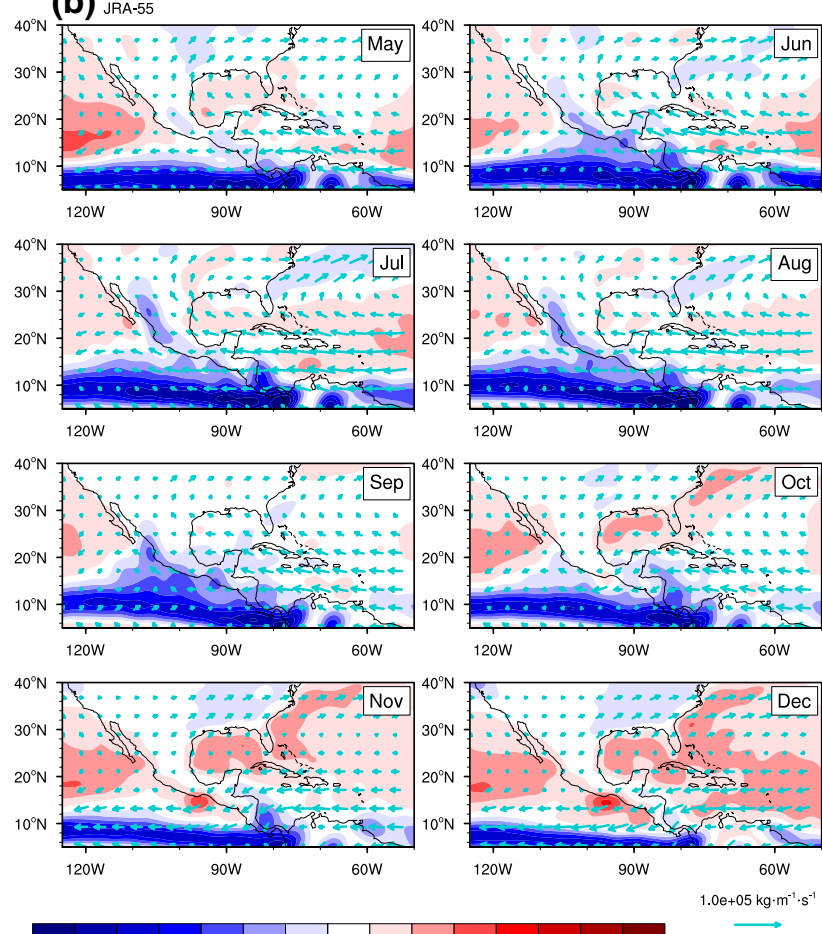

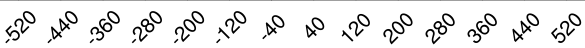

Fig. 7 Monthly-accumulated vertically integrated moisture flux (arrows; units: $\mathrm{kg} \mathrm{m}^{-1} \mathrm{~s}^{-1}$ ) and vertically integrated moisture flux divergence (shading; units: $\mathrm{mm}$ month $^{-1}$ ) by the mean circulation from a ERA-Interim and b JRA-55 reanalyses. Climatology for 1979-2016 (a) ERA-Interm
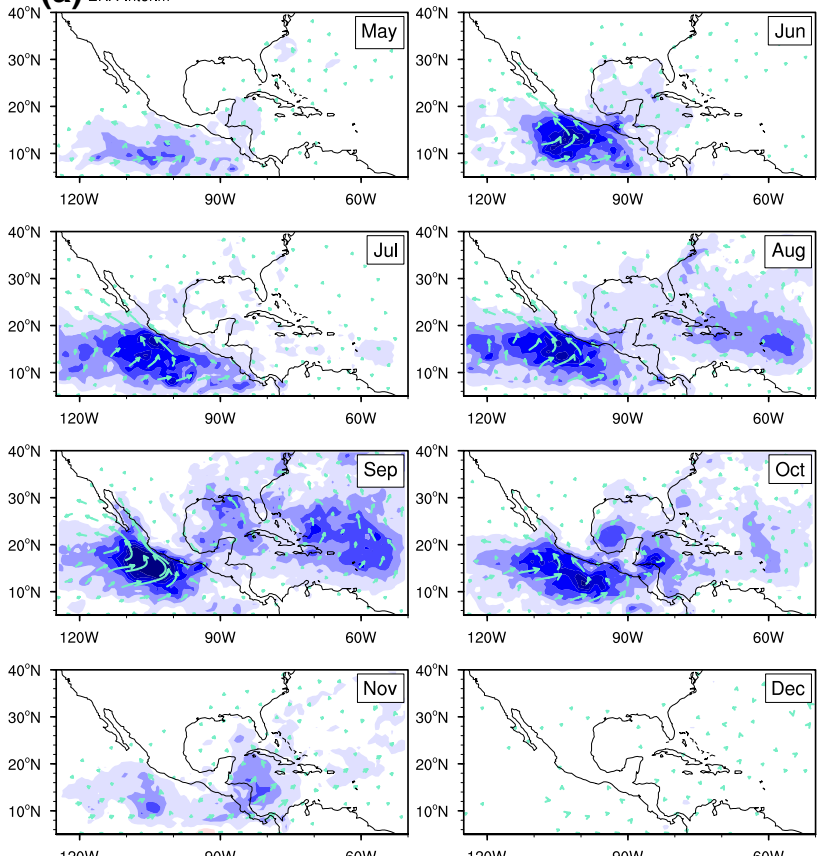

(b) ${ }_{\text {งคA.55 }}$
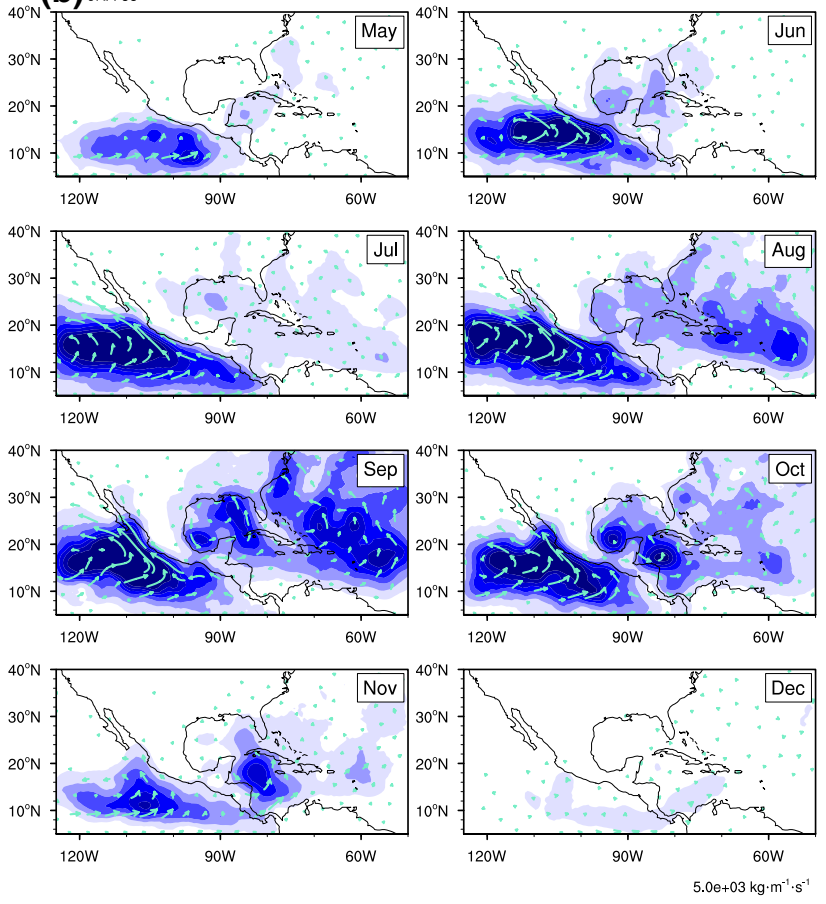

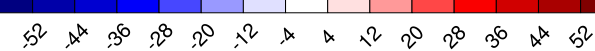

$\mathrm{mm} /$ month

Fig. 8 Monthly-accumulated vertically integrated moisture flux (arrows; units: $\mathrm{kg} \mathrm{m}^{-1} \mathrm{~s}^{-1}$ ) and its divergence (shading; units: $\mathrm{mm}$ month $^{-1}$ ) for TC eddies quantified by using fields and TCs tracks derived from a ERA-Interim and b JRA-55 reanalyses. Climatology for 1979-2016 
The contribution of TCs to moisture transport is highly relevant to the summer moisture availability over the domain: the Atlantic shows a predominant VIMF divergence during the year (Fig. 7) with some exceptions throughout the TC season (Fig. 7). Figure 9 shows in red (blue) areas where TC VIMF convergence reinforces (weakens) the moisture convergence (divergence) by the mean circulation, quantified with (a) ERA-Interim and (b) JRA-55. TCs activity widely influences the available moisture over both oceans and continent, particularly over southern and northeast Mexico, the west coast of Mexico, and the Gulf Coast of the U.S. Even more, both reanalyses show that TC-related moisture convergence has the capability to reverse the sign of the moisture divergence by the mean circulation on a monthly basis, particularly over a wide area of the Atlantic Ocean during September and October (shaded yellow areas of Fig. 9) when the monthly vertically integrated divergence of moisture by the mean circulation is weak.

\section{Discussion}

The motivation for this work comes from the need to quantify the climatological contribution of TCs to the atmospheric branch of the hydrological cycle over Middle America. It is important to understand the regional impact that TCs have on the seasonal water availability and in terms of extreme episodes of rainfall over Middle America, often linked with damages and losses of life. This study also contributes to a better understanding of the role of TCs in the global hydrological cycle.

An analysis of TCs contribution to monthly-accumulated rainfall and to extreme rainfall over Middle America is presented, based on TC tracks derived from observations (IBTrACS) and from TC tracks identified by an objective feature tracking method for ERA-Interim and the JRA-55 reanalyses, using TMPA 3B42 rainfall datasets for 1998-2016. Objective tracking methods allow identifying a more complete life cycle of the TCs, including the precursor and post-extratropical transition stages (Jones et al. 2003). This extends the observed record, assuming the reanalyses are accurate.

Distinct spatial distributions of quantified TC-related rainfall from observations and reanalyses were found: most of the discrepancies (agreements) occur over the Eastern Pacific and Central America (North Atlantic). TC contributions to rainfall quantified by reanalysis tracks over the Eastern Pacific (equatorward of $15^{\circ} \mathrm{N}$ ) show a larger monthly contribution compared with IBTrACS. This analysis indicates that TC tracks derived from reanalysis are able to capture the activity of precursors of TCs over the Eastern Pacific basin, and area of active generation of easterly waves (Ferreira and Schubert 1997; Serra et al. 2008; Toma and Webster
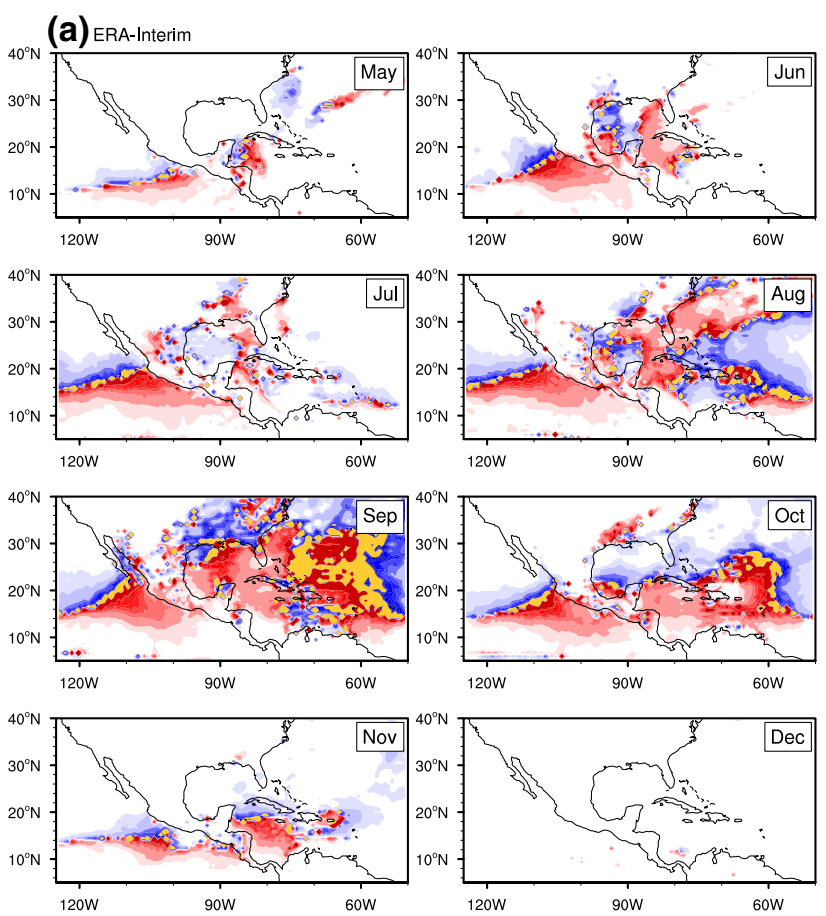

(b) JRA-55
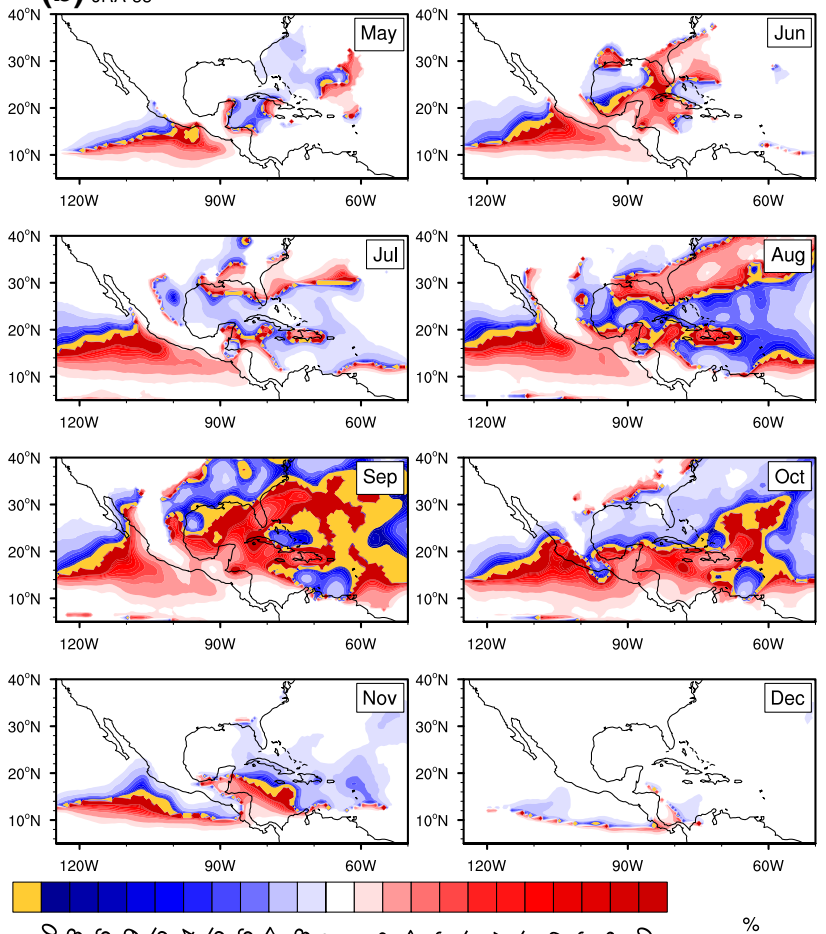

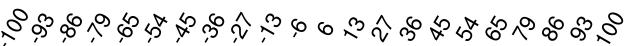

Fig. 9 Strength of the TC-associated VIMF convergence relative to the strength of the VIMF divergence by the mean flow (\%), estimated by using TC tracks from a ERA-Interim and b JRA-55 reanalysis. Shaded yellow areas indicate where TC reverses the sign of the divergence by the mean circulation. Climatology for 1979-2016 
Fig. 10 Differences between TC track densities based on ERAInterim reanalysis and IBTrACS a per year and $\mathbf{c}$ during JASO, and on JRA-55 reanalysis and IBTrACS b per year and $\mathbf{d}$ during JASO. Units: number of TCs per unit area $\left(\sim 10^{6} \mathrm{~km}^{2}\right)$. Period 1998-2016
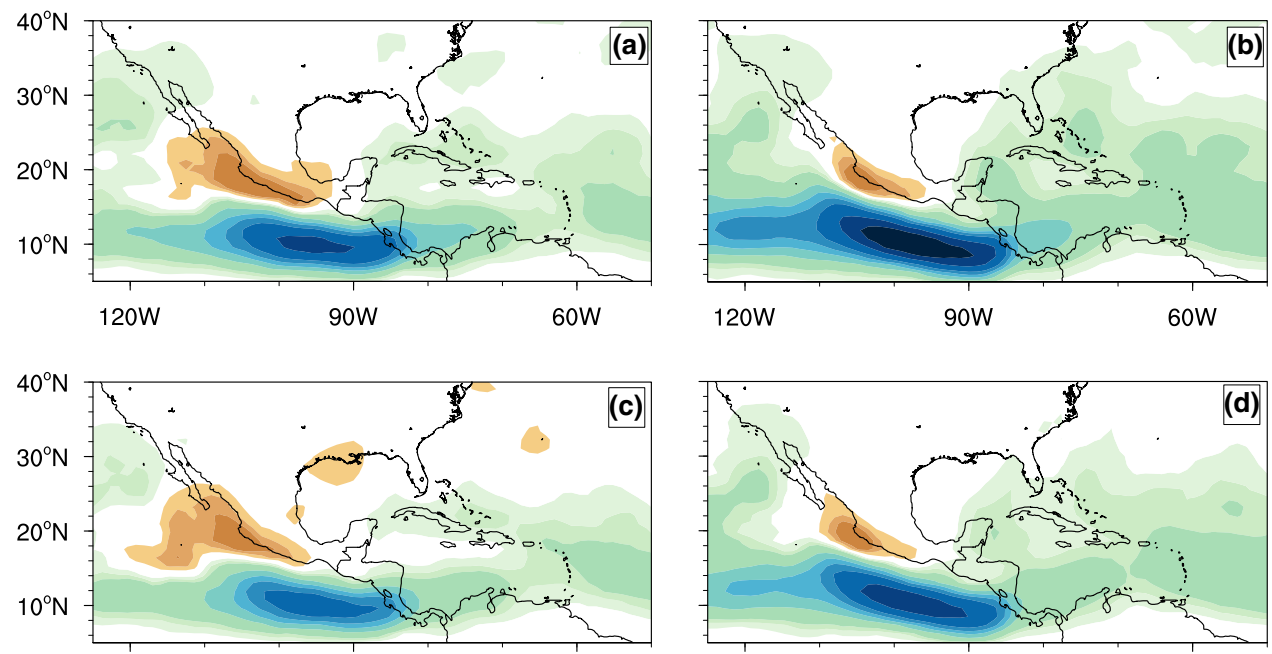

$120 \mathrm{~W}$

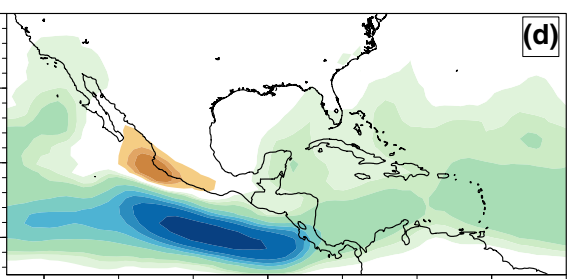

$120 \mathrm{~W}$

90W

$60 \mathrm{~W}$ 2010a, b) that are important precursors of TCs in the Eastern Pacific and North Atlantic basins (Belanger et al. 2016; Agudelo et al. 2011). The differences found over continental Mexico are mainly attributed to discrepancies in TC tracks in proximity to the coast (corresponding to post-TC stages). Using the extended TC lifecycle criterion for the reanalyses increases the TC contribution over most of Central America, including in regions where IBTrACS has few or no TCs. In these areas, there are substantial differences in estimated TC rainfall between using IBTrACS and reanalysis tracks.

The annual number of TCs detected in reanalyses over the Atlantic and Eastern Pacific basins are in good agreement with IBTrACS (Hodges et al. 2017). However, there are differences in the paths of the TCs identified in the reanalyses and IBTrACS, particularly for TCs that make landfall over continental Middle America (Fig. 10). In some cases, TC tracks derived from reanalysis are not tracked in the proximity to the coastline, and consequently the effect of the TCs on rainfall near the continent is less than when using IBTrACS. There is a strong similarity between the spatial patterns of the differences from reanalyses and IBTrACS in TC track density (Fig. 10) and TC related rainfall (Fig. 3). The differences in the quantification of TC-related rainfall are more noticeable over Mexico during September (Fig. 3). According to previous studies (e.g. Xu et al. 2017; Hodges et al. 2017), a significant source of error could come from the representation of the TC wind field in reanalyses, affecting the frequency and lifetime of TCs. Xu et al. (2017) argue that the combined effects of underestimated wind speed and overestimating the radial extent of TCs likely result in an underestimated TC-related moisture transport. However, the observed tracks are also subject to uncertainties in the identification of weaker TCs, due the different criteria employed by the various agencies to reporting an identified TC, resulting in the exclusion of some TCs from the Best Track, as well as the fact that some tropical depressions are excluded due to a lack of wind information (Hodges et al. 2017).

Chen et al. (2013) have found that TMPA 3B42 rainfall estimations related to TCs are better represented over ocean than over land, being particularly less accurate to capture orographic features during landfalling TC episodes. The retrieval method in TMPA 3B42 is based on the Goddard Profiling Algorithm (GPROF; Kummerow et al. 2001), which uses the contrast of the emissivity of the raindrops and the underlying surfaces to estimate rainfall rates [for further details consult Huffman et al. (2007)]. Over the ocean, the contrast of emissivity is better captured due to the well-defined difference between the rain and surface temperatures. As emissivity is heterogeneous over complex surfaces (such as the land), the contrasts between the emission of the rain drops and the surface are more difficult to capture, which reduces the accuracy of rain estimates (e.g. Chen et al. 2013). These uncertainties mean that our estimations of heavy rain frequency $(>50 \mathrm{~mm}$ ) of TC-related rainfall are uncertain over coastal and inland mountainous areas of Middle America.

Similar patterns and rates of TC-related extreme rainfall, quantified by using observations and reanalyses, are found. The agreement could be attributed to the fact that tracks calculated by using the objective TC identification scheme from reanalyses identify the strongest storms more accurately (e.g. Saffir-Simpson categories 4 and 5; Hodges et al. 2017). Moreover, observed tracks of strongest storms are more certain than those of weaker storms (e.g. tropical depressions, Saffir-Simpson categories 1-3), which increases our confidence in TC-extreme rainfall computed from observed 
and reanalysis tracks, as extreme episodes of rainfall are more likely to be related to the strongest storms.

TCs are important sources of moisture over the region, mainly during June to October. TC-related moisture convergence often extends further inland than TC-related precipitation, suggesting that TCs have a longer reach than their rainfall fields. Particularly, the Gulf of California, its continental surroundings and the North of Mexico receive moisture from TCs, which is comparable in magnitude to the amount of moisture extracted from the region by the mean circulation. More notably, the TC-associated VIMF convergence can reverse the sign of the VIMF divergence by the mean flow when the latter is weak, mainly over a big portion of the Atlantic Ocean and some continental regions during September and October.

Even though Central America experiences strong VIMF convergence during most of the year, the contribution of TCs is a non-negligible source of this moisture transport when a TC extended lifecycle criterion is considered. Added to this, the mean moisture transport over Central America is also likely related to the location and intensity of the ITCZ. TC contributions to moisture transport analyses suggest that a correct quantification relies heavily on the representation of TC tracks, and is strongly linked with the representation of the moisture flux in the reanalyses.

\section{Conclusions}

TCs are important sources of rainfall and moisture transport over Middle America, and make a substantial contribution to the amount of mean rainfall and the amount and frequency of extreme rainfall during the TC season. In this paper, a quantification of the climatology of TC-related rainfall and moisture transport over Middle America has been made, employing TC tracks from observations (IBTrACS) and twostate-of-the-art reanalyses: ERA-Interim and JRA-55. Our results show that the climatological mean rainfall contribution of TCs mainly occurs during September and October, when TCs in both the North Atlantic and Eastern Pacific are more active: TCs contribute about $10-20 \%$ of the monthlyaccumulated rainfall over the west coast of Mexico and centre of Mexico. The largest percentage of the monthly contribution over the entire Middle America domain was found in the southern Baja California Peninsula, with rates up to $60 \%$. Our analysis suggests that a shift in East Pacific TC tracks towards the western Mexican coast from September onwards is a main factor for the high TC contribution to the accumulated rainfall over the western continental portion of Mexico. The spatial distribution of TC rainfall over Northwestern Mexico might be related with static factors such as the orography. TCs are also important sources of extreme rainfall over Mexico and the North of Central America, in some cases contributing more than $50 \%$ of the monthly extreme rainfall amount, mainly during September and October when TCs tend to make landfall more often. Most of the agreements of spatial distributions of TC-related rainfall from observations and reanalyses are found in the North Atlantic basin, and in the contributions of TCs to extreme rainfall.

Most of the contribution of TCs to moisture transport occurs over coastal and Central Mexico, and the Eastern Pacific from June to October. TCs are likely to reverse the sign of the VIMF divergence when the VIMF divergence by the mean circulation is weak, occurring mainly in a wide area of the North Atlantic, and to a lesser extent, the Eastern Pacific, the Gulf of California and Northwestern Mexico. In this study, the robustness of the analysis of the regional contribution of TCs to the hydrological cycle heavily relies on the accuracy of the representation (location and lifetime) of the TC tracks, either based on observed TC-tracks or calculated from an objective tracking method applied to reanalysis datasets, as well as on the quality of the meteorological fields (e.g. estimations of rainfall and moisture flux from reanalysis). To improve our ability to quantify TCs contribution to rainfall and moisture, an accurate representation of the pre- and post-stage of the life cycle of the cyclones is required, including inland trajectories, no matter the stage of the TC lifecycle. This quantification of TCs contribution on the atmospheric branch of the hydrological cycle over Middle America will be useful to future studies on the understanding the sub-seasonal and inter-annual variability of the regional hydrological cycle, as well as process studies that investigate the role of TCs in the hydrological cycle.

Acknowledgements AFD was supported by The National Council of Science and Technology (CONACYT) Mexico as part of the Sectoral Fund CONACYT-Secretariat of Energy-Energy Sustainability, through a scholarship for PhD studies at the University of Reading. NPK was supported by the Natural Environment Research Council (NE/L010976/1). PLV, LG and MED were supported by the National Centre for Atmospheric Science, a collaborative centre of the Natural Environment Research Council, under contract R8/H12/83/001. We thank Dr. Kevin Hodges for helpful discussions regarding the objective TC tracking method and for providing us with the TC tracks from ERA-Interim and JRA-55 reanalyses. We also thank the Editor and anonymous reviewers for their valuable comments.

Open Access This article is distributed under the terms of the Creative Commons Attribution 4.0 International License (http://creativeco mmons.org/licenses/by/4.0/), which permits unrestricted use, distribution, and reproduction in any medium, provided you give appropriate credit to the original author(s) and the source, provide a link to the Creative Commons license, and indicate if changes were made.

\section{References}

Agudelo PA, Hoyos CD, Curry JA, Webster PJ (2011) Probabilistic discrimination between large-scale environments of intensifying and decaying African easterly waves. Clim Dyn 36(7-8):1379-1401 
Belanger JI, Jelinek MT, Curry JA (2016) A climatology of easterly waves in the tropical Western Hemisphere. Geosci Data $\mathbf{J}$ 3(2):40-49

Chen Y, Ebert EE, Walsh KJ, Davidson NE (2013) Evaluation of TRMM 3B42 precipitation estimates of tropical cyclone rainfall using PACRAIN data. J Geophys Res Atmos 118(5):2184-2196

Corbosiero KL, Dickinson MJ, Bosart LF (2009) The contribution of Eastern North Pacific tropical cyclones to the rainfall climatology of the Southwest United States. Mon Weather Rev 137(8):2415-2435

Dawson A (2016) Windspharm: a high-level library for global wind field computations using spherical harmonics. J Open Res Softw 4(1): $1-5$

Dee DP, Uppala SM, Simmons AJ, Berrisford P, Poli P, Kobayashi S, Andrae U, Balmaseda MA, Balsamo G, Bauer P, Bechtold P, Beljaars ACM, van de Berg L, Bidlot J, Bormann N, Delsol C, Dragani R, Fuentes M, Geer AJ, Haimberger L, Healy SB, Hersbach H, Hólm EV, Isaksen L, Kållberg P, Köhler M, Matricardi M, McNally AP, Monge-Sanz BM, Morcrette J-J, Park B-K, Peubey C, de Rosnay P, Tavolato C, Thépaut J-N, Vitart F (2011) The ERA-Interim reanalysis: configuration and performance of the data assimilation system. Q J R Meteorol Soc 137(656):553-597

Domínguez C, Magaña V (2018) The role of tropical cyclones in precipitation over the tropical and subtropical North America. Front Earth Sci 6:19

Ferreira RN, Schubert WH (1997) Barotropic aspects of ITCZ breakdown. J Atmos Sci 54(2):261-285

Gilford DM, Solomon S, Emanuel KA (2017) On the seasonal cycles of tropical cyclone potential intensity. J Clim 30(16):6085-6096

Grabowski WW, Moncrieff MW (2004) Moisture-convection feedback in the tropics. Q J R Meteorol Soc 130(604):3081-3104

Guo L, Klingaman NP, Vidale PL, Turner AG, Demory M-E, Cobb A (2017) Contribution of tropical cyclones to atmospheric moisture transport and rainfall over East Asia. J Clim 30(10):3853-3865

Hall T, Tippett MK (2017) Pacific hurricane landfalls on Mexico and SST. J Appl Meteorol Climatol 56(3):667-676

Hatsushika H, Tsutsui J, Fiorino M, Onogi K (2006) Impact of wind profile retrievals on the analysis of tropical cyclones in the JRA-25 Reanalysis. J Meteorol Soc Japan Ser II 84(5):891-905

Hodges K, Cobb A, Vidale P (2017) How well are tropical cyclones represented in reanalysis datasets? J Clim 30:5243-5264

Hodges K, Emerton R (2015) The prediction of Northern Hemisphere tropical cyclone extended lifecycles by the ECMWF Ensemble and Deterministic Prediction Systems. Part 1: Tropical cyclone stage. Mon Weather Rev 143:5091-5114 (Open Access)

Hodges KI (1994) A general method for tracking analysis and its application to meteorological data. Mon Weather Rev 122(11):2573-2586

Hodges KI (1995) Feature tracking on the unit sphere. Mon Weather Rev 123(12):3458-3465

Hodges KI (1999) Adaptive constraints for feature tracking. Mon Weather Rev 127(6):1362-1373

Huffman GJ, Bolvin DT (2015) TRMM and other data precipitation data set documentation. https://pmm.nasa.gov/sites/default/files/ document_files/3B42_3B43_doc_V7.pdf. Accessed 01 May 2018

Huffman GJ, Bolvin DT, Nelkin EJ, Wolff DB, Adler RF, Gu G, Hong Y, Bowman KP, Stocker EF (2007) The TRMM multisatellite precipitation analysis (TMPA): quasi-global, multiyear, combinedsensor precipitation estimates at fine scales. J Hydrometeorol $8(1): 38-55$

Jiang H, Zipser EJ (2010) Contribution of tropical cyclones to the global precipitation from eight seasons of TRMM data: regional, seasonal, and interannual variations. J Clim 23(6):1526-1543

Jones SC, Harr PA, Abraham J, Bosart LF, Bowyer PJ, Evans JL, Hanley DE, Hanstrum BN, Hart RE, Lalaurette F, Sinclair MR, Smith RK, Thorncroft C (2003) The extratropical transition of tropical cyclones: forecast challenges, current understanding, and future directions. Weather Forecast 18(6):1052-1092

Knapp KR, Kruk MC, Levinson DH, Diamond HJ, Neumann CJ (2010) The international best track archive for climate Stewardship (IBTrACS). Bull Am Meteorol Soc 91(3):363-376

Kobayashi S, Ota Y, Harada Y, Ebita A, Moriya M, Onoda H, Onogi K, Kamahori H, Kobayashi C, Endo H, Miyaoka K, Takahashi K (2015) The JRA-55 reanalysis: general specifications and basic characteristics. J Meteorol Soc Japan Ser II 93(1):5-48

Kossin JP (2018) A global slowdown of tropical-cyclone translation speed. Nature 558(7708):104-107

Kummerow C, Hong Y, Olson WS, Yang S, Adler RF, McCollum J, Ferraro R, Petty G, Shin D-B, Wilheit TT (2001) The evolution of the Goddard Profiling Algorithm (GPROF) for rainfall estimation from passive microwave sensors. J Appl Meteorol 40(11):1801-1820

Landsea CW, Franklin JL (2013) Atlantic hurricane database uncertainty and presentation of a new database format. Mon Weather Rev 141(10):3576-3592

Larson J, Zhou Y, Higgins RW (2005) Characteristics of landfalling tropical cyclones in the United States and Mexico: Climatology and interannual variability. J Clim 18(8):1247-1262

LeComte D (2014) International Weather Highlights 2013: Super typhoon Haiyan, super heat in Australia and China, a long winter in Europe. Weatherwise 67:20-27

Molinari J, Vollaro D, Skubis S, Dickinson M (2000) Origins and mechanisms of Eastern Pacific tropical cyclogenesis: A case study. Mon Weather Rev 128(1):125-139

NHC (2018). Tropical cyclone climatology. https://www.nhc.noaa.gov/ climo/. Accessed: 30 June 2018

Peixoto JP, Oort AH (1992) Physics of Climate. AIP-Press, American Institute of Physics, 1 edition

Prat OP, Nelson BR (2013a) Mapping the world's tropical cyclone rainfall contribution over land using the TRMM Multi-satellite Precipitation Analysis. Water Resour Res 49(11):7236-7254

Prat OP, Nelson BR (2013b) Precipitation contribution of tropical cyclones in the Southeastern United States from 1998 to 2009 using TRMM Satellite Data. J Clim 26:1047-1062

Prat OP, Nelson BR (2016) On the link between tropical cyclones and daily rainfall extremes derived from global satellite observations. J Clim 29(17):6127-6135

Sardeshmukh PD, Hoskins BI (1984) Spatial smoothing on the sphere. Mon Weather Rev 112(12):2524-2529

Serra Y, Braun J, Adams D (2016) Observing the intra-Americas sea climate: existing and emerging technologies. US CLIVAR Var 14:1-9

Serra YL, Kiladis GN, Cronin MF (2008) Horizontal and vertical structure of easterly waves in the Pacific ITCZ. J Atmos Sci 65(4):1266-1284

Toma VE, Webster PJ (2010a) Oscillations of the intertropical convergence zone and the genesis of easterly waves. Part I: diagnostics and theory. Clim Dyn 34(4):587-604

Toma VE, Webster PJ (2010b) Oscillations of the Intertropical Convergence Zone and the genesis of easterly waves Part II: numerical verification. Clim Dyn 34(4):605-613

Trenberth KE, Fasullo JT (2009) Global warming due to increasing absorbed solar radiation. Geophys Res Lett 36(7):1

Vigaud N, Robertson A (2017) Convection regimes and tropical-midlatitude interactions over the Intra-American Seas from May to November. Int J Climatol 37(S1):987-1000

Xu G, Osborn TJ, Matthews AJ (2017) Moisture transport by Atlantic tropical cyclones onto the North American continent. Clim Dyn 48(9):3161-3182

Publisher's Note Springer Nature remains neutral with regard to jurisdictional claims in published maps and institutional affiliations. 